\title{
Más allá del oka: otros modos de ser mujer mbyá guaraní ${ }^{1}$ Além do oka: outras formas de ser mulher mbyá guaraní
} Beyond the oka: other ways of being a mbyá guaraní woman

\author{
Alfonsina Cantore ${ }^{2}$ \\ Noelia Enriz ${ }^{3}$
}

DOI: http://dx.doi.org/10.20435/tellus.v19i39.598

\begin{abstract}
Resumen: En este texto nos proponemos analizar las transformaciones asociadas al liderazgo que atraviesan las mujeres guaraníes de la provincia de Misiones. La hipótesis central de esta exploración es que el rol de las mujeres guaraníes dentro de la comunidad se encuentra en un proceso particular de transformación, que aleja a ciertas mujeres del lugar históricamente más tradicional, ligado al ámbito doméstico y las relaciones con el propio grupo. Este rol se ve interpelado, tanto por los cambios dentro de los núcleos de la comunidad, así como por las nuevas subjetividades que emergen. Consideramos que en la cotidianidad as mujeres guaraníes se van posicionando en nuevos espacios y desarrollando habilidades específicas de los mismos que las diferencian, muchas de las cuales están potenciadas por la cotidianidad con la sociedad envolvente. Analizaremos los impactos de cacicas, auxiliares bilingües, agentes sanitarios y artesanas, y sus relaciones con el Estado, las ONG's y la propia comunidad, fundamentalmente a partir de registros propios de trabajo de campo etnográfico desarrollado en Iguazú desde 2013.
\end{abstract}

Palabras claves: género; liderazgos; mbyá guaraní; mujeres.

Resumo: Neste texto propomos analisar as transformações associadas à liderança que as mulheres Guarani atravessam na província de Misiones (Argentina). A hipótese central desta exploração é que o papel das mulheres guaraní dentro da comunidade se encontra em um particular processo de transformação que afasta a algumas mulheres do lugar historicamente

1 Se agradecen los comentarios de Lidia Schiavoni durante las II Jornadas de Cs. Sociales y Salud, Instituto de Medicina Tropical (Iguazú, Argentina).

2 Universidad de Buenos Aires/Instituto de Ciencias Antropológicas (UBA/ICA), Buenos Aires, Argentina.

3 Consejo Nacional de Investigaciones Científicas y Técnicas (CONICET)- Instituto de Altos Estudios Sociales/Universidad de San Martín (IDAES/UNSAM), Universidad de Buenos Aires (UBA), Buenos Aires, Argentina. 
tradicionais, ligadas ao espaço doméstico e as relações com o próprio grupo. Este rol é interpelado tanto por mudanças dentro da comunidade como, também, pelas novas subjetividades que emergem. Acreditamos que na cotidianidade as mulheres guaraníes se posicionam em novas âmbitos e desenvolvem competências específicas que as diferenciam, muitas das quais são potenciadas na interação com a sociedade envolvente. Utilizaremos os próprios registros de pesquisa etnográfica (desenvolvida em Iguazu, desde 2013) para analisar os impactos das cacicas, auxiliares bilíngues, agentes indígenas de saúde, artesãs, suas relações com o Estado, ONGs e da própria comunidade.

Palavras-chave: gênero; lideranças; mbyá guaraní; mulheres.

Abstract: The aim of this paper is analyze the transformations associated with the leadership that Guarani women go through in the province of Misiones (Argentina). The central hypothesis of this exploration is that the role of Guarani women within the community is part of a particular process of transformation, which distances certain women from the historically more traditional place, linked to the domestic sphere and the relations with the whole group. The traditional role is changing, both by the adjustment within the nuclei of the community, as well as by the new subjectivities that emerge. In everyday life, Guarani women are positioning themselves in new spaces and developing specific skills that differentiate them, from many of which are enhanced by daily life with the surrounding society. We will analyze the impacts of cacicas, bilingual auxiliaries, health and artisan agents, and their relations with the State, NGOs and the community itself, mainly from records of ethnographic field work developed in Iguazú since 2013.

Keywords: gender; leadership; mbyá guaraní; woman.

\section{INTRODUCCIÓN}

Las actividades que realizan hombres y mujeres indígenas han sido caracterizadas por la antropología tradicional a través de una supuesta división del trabajo por sexo que atribuía ciertos papeles, valores y expectativas diferenciales. Este tipo de descripciones asimilaron las tareas de hombres y mujeres a particularidades biológicas sin tener en cuenta las construcciones sociales sobre los géneros (SCOTT, 2010; MOORE, 2009). Estas tareas se compadecen con las representaciones generales de las mujeres indígenas y, en términos muy generales con los roles asociados a las mujeres, entendidos como construcción social y discutidos desde la antropología feminista (MOORE, 2009; LAMAS, 1999; MOHANTY, 2008 entre otras). En Argentina, si bien la literatura etnográfica más reciente se esmera en revertir esta postura las investigaciones que focalizan en 
las mujeres indígenas son escasas (HIRSCH, 2008; GÓMEZ, 2016; CASTELNUOVO, 2015; HECHT et al., 2018) y solo recientemente comenzamos a dar cuenta de la singularidad de las experiencias de mujeres mbyá guaraní (GARCÍA PALACIOS et al., 2016; CANTORE, 2017).

Desde las primeras etnografías que se interesaron por los guaraníes (CÁDOGAN, 1997; SCHADEN, 1998; SUSNIK, 1983) se ha asociado los quehaceres de las mujeres con la maternidad, el cuidado de los niños y las niñas, las labores de alimentación y producción de alimentos para el consumo (que pueden ser tanto tareas de recolección como de limpieza y almacenamiento). Estos mismos elementos aparecen reeditados en antropólogas/os contemporáneas/os que recuperan roles tradicionales de las mujeres en sus experiencias etnográficas. Las descripciones incluyen el modo en que las niñas comienzan a incorporar los trabajos y hábitos del hogar en referencia a otras mujeres (LARRICQ, 1993), como también, su rol como cuidadoras de la familia, especialmente, de las niñas y los niños (REMORINI, 2003) y lo que se espera de ellas al llegar la primera menstruación donde escuchan los consejos para transitar esa experiencia ${ }^{4}$ (CEBOLLA BADIE, 2014). En este texto nos proponemos dar cuenta de otros roles que las mujeres mbyá desarrollan y que amplían los horizontes tradicionales establecidos para ellas. Si bien en nuestros trabajos de campo hemos registrado innumerables casos de mujeres cumpliendo las tareas tradicionales, consideramos que no son sus únicos espacios de competencia, ya que reconocemos otras experiencias que ellas desarrollan afirmadas en su identidad de género y étnica. Registramos el rol de ciertas mujeres en la toma de decisiones familiares como también políticas de sus grupos, vimos cómo se disponen a encarnar la representación de sus comunidades, cómo interactúan cotidianamente con la sociedad envolvente, entre otras. Tal como adelantamos, nos proponemos visibilizar otras experiencias que desarrollan las mujeres mbyá guaraní de la provincia de Misiones. Nuestra hipótesis central es que en la sociedad mbyá

\footnotetext{
4 "Desde las primeras observaciones sistemáticas conocidas, se expresa que para los mbyá la menarca constituye una crisis de grandes proporciones. Así, se sostiene que 'no hay duda de que la primera menstruación es tenida como el acontecimiento responsable por la manifestación de la crisis más delicada de la vida de la mujer Guaraní' (Schaden, p. 108). Una vez anunciada su llegada en una niña, se desarrolla una ceremonia particular, la ñemondyiá: 'los Mbyà guaraní someten a la muchacha púber a una rigurosa observancia ritual; se la recluye en un rincón de la vivienda, con cara a la pared, por espacio de tres semanas; no debe hablar, reírse, rascarse o ya soplar el fuego' (Müller, p. 188)" (ENRIZ; GARCÍA PALACIOS, 2008, p. 218).
} 
guaraní se habilita la posibilidad de que las mujeres desarrollen diversas tareas muchas de las cuales se ven potenciadas en su vínculo con la sociedad envolvente.

Consideramos que los liderazgos que emergen a partir de las relaciones interétnicas dan lugar a esos cambios. Como bien explica Ana María (GOROSITO KRAMER, 2006), los liderazgos de las poblaciones guaraníes han cambiado a lo largo del tiempo. Una de las transformaciones más centrales tiene que ver con la incorporación de un nuevo tipo de autoridades a las comunidades, denominados caciques. Los caciques no forman parte de las autoridades tradicionales, que se pusieron de manifiesto históricamente en las personas más ancianas de las comunidades, más frecuentemente hombres. Mientras que los ancianos y las ancianas de las comunidades, opyguas, lideran en lo espiritual y, por tanto, aconsejan en los términos generales de la vida, los cacicazgos representan otra cosa. Los caciques forman parte de un tipo de autoridad creado por el Estado o mejor dicho, a pedido del Estado en su búsqueda de nexos concretos y sencillos con las comunidades. Lo relevante para nosotras en esta oportunidad es que la autora pone de manifiesto la posibilidad de transformación de los roles de autoridad. A esta esfera corresponde la primera parte de este texto en donde haremos referencias al dominio de las mujeres en el espacio político que no escapa de las relaciones de género comunitarias, pero en donde se encuentran estrategias y tácticas para ser escuchadas por el grupo y guiar a la comunidad.

En esta misma línea, en un segundo apartado, nos proponemos problematizar el surgimiento de nuevos roles que surgen, también, a la luz de las demandas del Estado: los roles de auxiliares bilingües escolares y agentes sanitarios/ as interculturales. Pero no nos interesan solamente por ser nuevos actores que portan diferentes formas de autoridad, sino porque incorporan un elemento de transformación en otro plano: las mujeres mbyá ocupan gran cantidad de estos cargos. Por último, aludimos a las mujeres artesanas y su desempeño en el marco del turismo, en la comercialización de artesanías como una esfera de competencia de las mujeres y que no puede ser pasada por alto en la zona donde surgen nuestros registros: Iguazú, el principal punto turístico de la provincia de Misiones y uno de los más distinguidos en Argentina.

Metodológicamente, sostenemos nuestra reflexión en el trabajo de campo etnográfico, complementado con entrevistas abiertas, enmarcadas en historias 
de vida en proceso de avance. Ambas autoras realizamos trabajo de campo, de tiempos variables, en núcleos mbyá ubicados en la zona rural de Iguazú desde 2013 y 2015, si bien Noelia Enriz ha realizado trabajo de campo en otras comunidades de la provincia entre 2003 y 2010. Del conjunto de estos trabajos surgen registros de campo conjuntos como principal fuente de datos para este texto. A su vez, acompañaremos la fundamentación con notas periodísticas a los efectos de complementar con registros de otras zonas de la provincia.

\section{REPRESENTANTES}

Para Cadogan (1997), referencia insoslayable a la hora de reflexionar sobre estas poblaciones en términos diacrónicos, el poder en las poblaciones mbyá no estuvo alejado de las referencias a la construcción de lo religioso. Es a partir de los liderazgos religiosos que se conforma un escenario de distribución de atributos y poder que atraviesa aspectos de lo religioso permeando diversos planos de la vida de las comunidades. Quizá, las características que tenían los Estados nacionales y la relación que los mismos desarrollaban con los y las indígenas, en los tiempos en que Cadogan realizaba su etnografía, hayan diluido la posibilidad de que esta pregunta se correspondiera con sus intereses. Quizá, haber sido un hombre de fe lo llevó a adentrarse tan profundamente en la perspectiva religiosa de este grupo dejando otros aspectos del poder fuera de su mirada. Lo cierto es que desde su perspectiva el poder queda alojado en lo xamanico. Schaden (1998), por su parte, considera que son los procesos de contacto son los que revitalizan a la religión como refugio. Al revisar esta discusión Pissolato (2007) adhiere a la perspectiva de Schaden, también presente en la obra de Hélène Clastres (1993).

Retomando la propuesta de Gorosito Kramer (2006) expuesta en la introducción, que refiere a la incorporación de cacicazgos políticos generados por el Estado con la finalidad de una negociación más directa con las comunidades, es que se observa cómo las autoridades comunitarias quedan divididas entre aquellas encargadas de los nexos con los y las no-indígenas y, aquellas, a través de las cuales se ejerce la comunicación con los dioses. Entre los guaraníes, existe un conflicto trascendental que es poder interpretar las palabras de los dioses en la guía de las propias comunidades. El atributo de poder que supone para las comunidades lograr la capacidad de interpretar la palabra de los dioses, impregna el resto de las 
dimensiones sociales del poder ya que interviene en atributos que se dan, luego, entre los seres terrenales. Un elemento emblemático de la distancia entre formas de poder es la lengua, mientras para ser líder espiritual, opyguas, se espera que los sujetos sean muy hábiles en la lengua indígena o incluso que no utilicen otra lengua para comunicarse en lo cotidiano- lo que lleva a los ancianos a procurar hablar solo en mbyá como estrategia de profundización de su espiritualidad- para ser cacique se esperan habilidades de traducción de las ideas mbyá al español y buen desempeño comunicativo en esta lengua.

Las transformaciones del liderazgo indígena en la provincia de Misiones se expresan fuertemente en diversos planos cotidianos. A continuación, recuperamos una experiencia de campo que nos permite visibilizar de qué modo las tensiones entre el liderazgo religioso y su atribución de poder a los liderazgos políticos. En el caso que analizaremos a continuación el conflicto de obediencia de la comunidad al liderazgo religioso termina por disolver vínculos ante la imposibilidad de establecer consensos.

Durante diversas etapas de trabajo de campo entre los meses de marzo y octubre de 2016 asistimos a las deliberaciones que una comunidad de la zona de Iguazú desarrollaba para arribar consensuadamente a una nueva autoridad política, un nuevo cacique. El anterior, quien ejerció ese rol por varios años, había sufrido un accidente automovilístico, sin secuelas físicas. La situación traumática lo llevó a decidir alejarse de ese cargo hasta sentirse nuevamente fortalecido para desempeñarlo. Las deliberaciones para lograr una nueva autoridad suponían asambleas largas y masivas, seguidas de reflexiones privadas y domésticas, para volver luego a las asambleas. En este proceso, que duró muchos meses ciertas voces cobraban notoriedad, especialmente las de los y las ancianos/as. Por momentos se erigían autoridades, que no lograban suficiente legitimidad y terminaban cayendo. Esas autoridades eran puestas a prueba, a pesar de nunca lograr el consenso comunitario. (Registro conjunto, 25/10/2016)

Lo que emerge claramente en nuestras investigaciones es que los ámbitos de poder, de diversas escalas, forman parte de una trama que siempre cuenta con avales de los líderes espirituales. Sin que los y las ancianos/as lo celebren, no se desarrollaran firmemente las autoridades. Y en contrapartida, si ellos y ellas son desoídos, la comunidad como tal debe de algún modo "refundarse y reorganizarse". Es esta la situación que atravesó la comunidad a la que estamos refiriendo, la cual registramos en nuestro diversos trabajos de campo: 
El largo proceso de definición de autoridades políticas costó concretarse debido a que un grupo liderado por el cacique anterior y, otro, por la mujer más anciana del núcleo y líder espiritual disputaban ideas contrapuestas respecto de quién debía ser elegido para ocupar ese cargo. El parentesco intervenía en esta disputa, ya que mientras la abuela pugnaba por posicionar a un miembro directo de su parentela, el cacique saliente se inclinaba por ubicar en ese rol a un hombre de su confianza manteniendo en cierta medida la posibilidad de intervenir en las decisiones que éste tomara.

Finalmente, en una de las asambleas se consensuó a favor de quien había sujeto indicado por el cacique saliente. Luego de este episodio, la anciana decide mudarse con toda su familia y formar una nueva comunidad a unos $80 \mathrm{~km}$ de Puerto Iguazú. Esta mudanza implicó la reestructuración de la comunidad, sobre todo en el plano religioso, ya que era ella quien llevaba adelante las ceremonias. Esto pudo ser registrado en nuestras posteriores visitas al núcleo, porque resultó dificultoso que las personas pudieran referirnos a una autoridad ceremonial consolidada, nunca lograban ponerse de acuerdo. Finalmente, las disputas de poder entre la líder espiritual y quien desempeñó el rol de liderazgo político, dieron como resultado la partida de una familia ampliada (la de la anciana) de la comunidad en cuestión y su partida deterioró el rol político del nuevo líder elegido. Éste último perdió su estatus en un corto plazo y fue reemplazado. En nuestras últimas visitas (febrero 2018) un nuevo cacique intentaba lograr legitimidad del grupo con continuos apoyos por parte de algunas personas de la comunidad. Mientras que la organización política-religiosa aún no ha logrado estabilizarse. (Registro conjunto, 2017-2018).

Esta experiencia da cuenta de cómo, las autoridades tradicionales y las nuevas, o bien las autoridades religiosas y las políticas, forman parte de una experiencia conjunta de conducción de la comunidad como tal. Y en esa medida, de cómo las distancias o las faltas de acuerdos imposibilitan una conducción armónica. Las divisiones al interior de los núcleos responden al desplazamiento como característica que atañe al grupo y que, en este caso, se presenta como una estrategia para resolver conflictos internos: la disputa sobre las autoridades del grupo se resuelve mediante el distanciamiento llevado adelante por la mujer más anciana de la comunidad.

Las tareas de cacicato han sido siempre realizadas por hombres para ser quienes interactúan con los no-indígenas. Sin embargo, a través de nuestro trabajo de campo pudimos constatar que el rol de las mujeres en relación con la organización de las comunidades es muy preponderante. En una conversación sobre 
la ocupación de unas tierras en la zona de Iguazú, el cacique le refiere a nuestra compañera Clara Boffelli la siguiente historia:

Me dice que con su mujer venían pensando ubicarse en estas tierras como hace un año y seis meses, porque ella lo soñó, los soñó a ellos en ese lugar. Y entonces él le preguntaba cómo iban a interpretar ese sueño [...] Entonces esperaron el momento y a los 6 meses su esposa volvió a tener otro sueño [...] y volvió a soñar, entonces visitaron este lugar, y lo eligieron. El último sueño que ella tuvo: hay muchas vacas en el territorio, pero ella sabe que son personas. (Registro Boffelli, 18/9/2015).

¿Ella promovió el cambio? Lo que podemos afirmar es que las referencia de las autoridades de la comunidad sobre el cambio están relatadas de tal modo que indican a esta mujer como motor de ese cambio, la conformación de algo nuevo a partir de los sueños, narrados como mensajes de los dioses que deben interpretarse para entender el accionar. Si bien aquí, tanto el cacique (representante de esta lucha territorial frente a la sociedad) como la autoridad religiosa son hombres, se coloca en el potencial onírico de esa mujer el disparador del cambio de todo el grupo.

Aunque son excepcionales, podemos reponer experiencias de mujeres mbyá que asumen la representación de sus comunidades frente a los organismos políticos específicos. Estas tareas, de cacicato, no suponen una formación específica, pero sí una serie de cualidades para generar los diálogos necesarios entre el grupo que se representa y los efectores del Estado.

Entre las cualidades se encuentra la posibilidad de abrir diálogos, lo que supone entre otras cosas, ser muy bilingües. Como mencionamos anteriormente, las habilidades de traducción, lingüística y conceptual, de los intereses mbyá frente a las dinámicas institucionales son un valor central para representar al grupo en los organismos de gobierno. $Y$ este dato no es menor si consideramos que las cifras censales dan cuenta de mayores niveles de monolingüismo mbyá entre las mujeres. Esta tarea, a su vez, implica poder administrar recursos, simbólicos y materiales en pos de la comunidad que se representa y de su desarrollo.

En la provincia se registran cinco núcleos con mujeres como cacicas. Recientemente una locación ubicada en el centro oeste de la provincia se ha sumado a esta particularidad. En dicho núcleo, según relatan en distintas notas periodísticas las cacicas elegidas, las mujeres no sabían que podían cumplir esa 
tarea, lo que las llevó a viajar a Posadas e informarse en la Dirección de Asuntos Guaraníes. Esta travesía las enfrentó con discursos y miradas peyorativas hacia ellas por parte de algunos hombres de comunidad como el cacique anterior quien cuestionaba que las mujeres puedan desempeñar ese rol. Al respecto las actuales representantes de esta comunidad exponen en una entrevista periodística:

Él decía: "qué va a hacer una mujer en Posadas, las mujeres no saben nada", pero nosotras las mujeres tenemos derechos y tenemos la forma y encontramos ayuda, vamos a tocar puertas y muchas se abrirán, se cerrarán algunas pero tengo apoyo de los blancos, gracias a ellos tenemos cosas avanzadas, que las mujeres estén confiadas: ellas también tienen derechos, hay mujeres que son maltratadas y deben saber de sus derechos. (MISIONES ONLINE, 2015a).

A pesar de las claras estigmatizaciones de género obtuvieron la mayoría en asamblea para posicionarse en ese rol. Mayoría que estuvo apoyada principalmente por las otras mujeres de la comunidad. Según relatan estas cacicas el foco de sus políticas estaría puesto el cuidado de la familia principalmente: cuestiones ligadas a la salud, enfermedades de transmisión sexual y asistencias sociales como la tarjeta alimentaria, priorizando a las mujeres, niños y ancianos. Ellas mismas representan el cambio y la posibilidad de que las mujeres ocupen roles de representación al declarar en una entrevista: "En la aldea prefirieron elegir a mujeres porque creen que podemos mejorar cosas que están sucediendo" (MISIONES ONLINE, 2015a) y ponen de manifiesto que pensaban que las mujeres no podían formalmente ocupar esos roles. Incluso habiendo otras mujeres en ese rol desde hace más de 5 años.

Las tareas de cacicato no son los únicos espacios en donde las mujeres pueden discutir con las formas hegemónicas de género impuestas por el grupo mbyá. De hecho, se trata solo de cinco núcleos de cien en total que se contabilizan actualmente. Como venimos resaltando, las relaciones interétnicas y el Estado moldean algunas de las experiencias de las mujeres. Las dinámicas sociales implican transformaciones de este ethos que llamamos cultura. Como indicamos en la introducción a este texto, toda la bibliografía sobre la región guaranítica da cuenta de transformaciones en los roles de liderazgo. De la aparición de nuevos actores y de la re-significación de las autoridades tradicionales. Lógicamente, estas transformaciones se dan a la par de los cambios contextuales que se desar- 
rollan en los entornos concretos, algunos asociados a dinámicas de los Estados nación y otros del desarrollo empresarial capitalista. Ambos promueven figuras centralizadas, que acumulen el poder y puedan ser efectores únicos de un diálogo asimétrico inevitable.

Otros ámbitos en los que se expresan estas disputas y resistencias son el educativo, el sanitario y el turismo - este último especialmente en la zona de Iguazú por el desarrollo del turismo de gran escala en la zona. Cumplir con estos deberes implica constantes encuentros interétnicos en el día a día, ya que se trata de indígenas que, a su vez, son representantes estatales. Como dan cuenta los registros periodísticos, las actividades de cacicazgo sumado a las de agentes sanitarios y auxiliares bilingües son tradicionalmente reconocidas como tareas masculinas. Quizás se deba a que el encuentro con el blanco aumenta la figura de hombre, acrecienta el afuera, el monte, la caza y lo público, es decir, enfatiza en aquellas actividades representadas como "masculinas" (SEGATO, 2010) yuxtaponiendo lógicas de género occidentales e indígenas que dejan a la mujer por fuera de estos ámbitos (GÓMEZ, 2013). En el próximo apartado nos proponemos agudizar estas preguntas respecto de cómo se arriba a acuerdos de poder al interior de las comunidades guaraníes a partir de reflexionar sobre nuevos roles de poder, de muy reciente creación y las dinámicas que atraviesan. Nuestro interés mayor será poder ver de qué forma las mujeres se posicionan en esta transformación.

\section{CUIDADORAS}

Como venimos desarrollando los procesos de construcción de poder en las poblaciones guaraníes son atravesados por las dinámicas de la sociedad envolvente. En este apartado nos preguntamos respecto de las transformaciones que han traído a las comunidades la presencia de nuevos actores que articulan con el Estado, por las responsabilidades sociales que ellos tienen, pero especialmente por las dinámicas que se desarrollan hasta que son designados con esos atributos. La pregunta supone una segunda instancia asociada a las transformaciones que atraviesan las mujeres mbyá cuando son incorporadas en este tipo de roles.

Las comunidades mbyá de la provincia de Misiones cuentan en una inmensa cantidad de personas que articulan con el Estado. Sobre todo, en las nuevas 
comunidades que se van fundando es habitual escuchar la frase "Queremos tener escuela y salita" en referencia al acceso a la Escuela Intercultural Bilingüe (EIB) y a los Centros de Atención Primaria de la Salud (CAPS). Tener escuela con EIB y CAPS se ha construido como una demanda generalizada de la población mbyá para la mayoría de las comunidades de la provincia. Con la escuela y la "sala" Ilegan inexorablemente las designaciones de cargos de Auxiliares Bilingües ( $A B$ ) y Agentes Sanitarios (AS). Decimos la gran mayoría, porque existen notables excepciones a este modelo, también ${ }^{5}$.

Estas actividades que suponen una tarea laboral específica, con retribución económica y responsabilidades fuera de su familia nuclear, exigen también requisitos previos de formación en la temática que generalmente se adquiere a partir de una capacitación específica recibida en ámbitos formalizados por el Estado, fuera de los propios núcleos de habitación. Estas tareas se encuadran en actividades que demandan relaciones permanentes con el afuera de la comunidad y, en el caso de los roles estatales, suponen articulaciones con programas específicos y una jerarquía institucional compleja.

La interacción con la sociedad envolvente re-posicionan las dinámicas de poder al interior de los grupos, ya que otorga la posibilidad de asignar recursos materiales y simbólicos a un sujeto, y a través de este a la comunidad como tal. Por ejemplo, el caso de Matilda como agente sanitaria nos parece ilustrativo:

Conocemos a Matilda desde 2012, es madre y vive en Iguazú desde que formó pareja. En el último año fue elegida como agente sanitario. Según su relato a ella le interesan las cuestiones de salud, pero también se agota con esta tarea, que debe cumplirla porque la eligieron y confiaron en ella. Es habitual verla cansada, por ejemplo, un día nos dijo que no se sentía dispuesta para hablar con nosotras porque "había tenido un día muy largo. A las seis de la mañana había acompañado a una chica embarazada para controles, después volvió a la comunidad para acompañar al hospital a un bebe que tenía neumonía y quedo internado. Cuando llego del hospital a las 13 fue a una asamblea que hubo por eso termino almorzando alrededor de las 3 de la tarde". (Registro conjunto, 1/11/2016).

En otras charlas que se desarrollan en el patio de su casa, con su fogón y sus niños deambulando, nos cuenta sobre algunas problemáticas que enfrenta:

$\overline{5}$ Se registran algunos casos en la reserva de biósfera Yabotí (Misiones, Argentina). 
la ausencia de medicamentos, las necesidades económicas, los cambios de autoridades, articulaciones con la escuela como agente sanitaria, entre otras.

A diferencia de los roles de cacicas, las tareas de Agente Sanitario y Auxiliar Bilingüe se implementaron en un contexto que permitió a las mujeres incorporarse desde el inicio de este desempeño. De tal modo que nunca fueron roles exclusivos de cierto género, sino que se distribuyeron desde el inicio.

Las propuestas estatales en salud y educación son generales a toda la población indígena del país. Existen dos normativas legales nacionales que promueven la formación de referencias concretas que vinculan lo indígena y lo estatal, actores sociales cuyo desempeño está formalizado y regulado. En cuanto a la educación, se fomenta la creación de escuelas de modalidad EIB en el marco de la Ley Nacional de Educación 26.206 (2006) y con ella la formación de auxiliares bilingües indígenas. Por otro lado, la Ley 23.302 (1985) promueve la creación de cargos de agentes sanitarios interculturales. A su vez, la provincia produce la articulación local y diseña las capacitaciones concretas.

Por otro lado, quienes deben cumplir con estas tareas son elegidos también en asamblea y por consenso. Y con la misma dinámica son removidos de sus roles. Como dijimos estos espacios pueden ser aprovechados por las mujeres, en Iguazú registramos más agentes sanitarias que auxiliares bilingües y durante nuestros primeros años de trabajo de campo que quienes ocupan la primera tarea decían no gustarle su trabajo, siendo un puesto con un alto nivel de rotación (lo que con el tiempo se modificó), mientras los segundos suelen estar más tiempo cumpliendo esta función, es decir, ser más estables.

Como expresamos anteriormente, Matilda como promotora sanitaria lleva al frente las demandas comunitarias sobre la salud, pero también le interesa articular con la escuela. En una ocasión a Matilda le pidieron que hable en la escuela sobre educación sexual exigiendo que lo haga con todo el grupo. Sin embargo, ella dice no haberse animado a hacerlo públicamente con hombres y mujeres y buscó como estrategia trabajar el tema por separado. Esta situación le generó muchas dudas sobre los conocimientos médicos que tenían los chicos y las chicas sobre métodos preventivos y nos dijo al respecto "en la salita hay preservativos pero no los van a buscar, no sé si por vergüenza o porque no los usan" (entrevista conjunta, 31/05/2016). A partir del registro podemos apreciar como 
Matilda no sólo ingresó al mercado laboral como agente sanitaria, lo que incluyó una reorganización en su vida cotidiana como marcamos anteriormente, sino que también debió formarse en una gran cantidad de temas que pasan a ser parte de su cotidiano como, por ejemplo, encontrar estrategias para responder no sólo a la comunidad sino también a la escuela y CAPS.

La situación de las mujeres que se dedican a tareas docentes, implica también una sobre carga, así como lo manifestado para el rol de Agente Sanitario. En muchas comunidades se eligen mujeres para el desempeño del rol de Auxiliar Bilingüe, algunos de los argumentos para sostener este vínculo remiten al rol materno. El desempeño como AB supone la articulación de los intereses formativos que la comunidad tiene en el desarrollo de sus niños y niñas con los que persigue la escuela como institución. Para lograr representar los intereses del propio grupo se desarrolla la asignatura de "Cultura mbyá" cuyo contenido delinean los AB junto con las autoridades del grupo. Para acompañar los objetivos institucionales, en muchas ocasiones, los AB funcionan como traductores. Si bien en Iguazú no hemos registrado mujeres cumpliendo este rol, en la investigación doctoral de Noelia Enriz recopila estas experiencias en otras zonas de la provincia:

Alicia era la $A B$ del prescolar recientemente inaugurado. Más allá de su capacitación la comunidad la había elegido por su vinculación con el opygua, que era su padre. Alicia era madre de 5 niños de los cuales 3 asistían a la escuela con ella. Manifestaba cotidianamente cansancio por la gran cantidad de tareas que debía cumplir. En el aula, funcionaba permanentemente como traductora, porque los niños ingresantes no hablaban español. A su vez, contaba narraciones en la materia propia. Luego se dedicaba a la crianza de sus hijos. Y por este mismo motivo, no asistía a las capacitaciones para $A B$ que brindaba la Dirección de Interculturalidad. (Registro Enriz, CentroOeste, 2008).

Los roles de $A B$ y AS son roles con designación y financiamiento de los organismos de gobierno, lo implica una diferencia relevante con el rol de Cacicazgo. A su vez, implica una transformación en las dinámicas familiares, ya que un miembro de la familia pasa a tener un salario regular y por tanto el dinero comienza a formar parte del entramado cotidiano. 


\section{ARTESANAS}

Como anticipamos, el turismo es otra actividad de la que no están exentas las mujeres. Nuestro trabajo de campo se desarrolla en Iguazú, una zona de gran desarrollo de la industria del turismo a gran escala, por la presencia de las Cataratas homónimas. Esta coyuntura, ha llevado a las comunidades a participar de diverso modo de emprendimientos turísticos. Aunque de manera muy desventajosa, algunas familias han sabido insertarse en labores turísticas. En general, la forma de introducirse en estas actividades ha sido la articulación-no siempre equitativa- con otros actores. Es así que una de las locaciones de Iguazú lleva a cabo un programa de promoción del turismo con apoyo de una ONG. La referente zonal de la organización tiene un fuerte esmero por incorporar mujeres mbyá al proyecto, aunque encuentra dificultoso que ellas se sumen. En una conversación informal nos relata que "en una oportunidad pidieron [a la comunidad] que sumaran alguna mujer al proyecto, pero lo hicieron únicamente en tareas de limpieza" (entrevista conjunta, 03/09/15). A pesar de su insistencia en que ellas lleven adelante visitas turísticas, sólo tenemos registro de una muchacha que ofició como guía, pero al poco tiempo dejó esta tarea.

Hemos podido relevar que la principal actividad turística de las mujeres es la venta de artesanías. Podemos ver a las mujeres adultas y jóvenes en la comercialización de las artesanías, que muchas veces las producen en sus hogares entre todos los miembros. Ellas se han mostrado muy hábiles para la negociación y comercialización. Las mujeres venden en la ciudad con puestos improvisados, así como en los puestos de venta de artesanías que se ubican al interior de las locaciones, en el Parque Nacional Cataratas del Iguazú o bien en los puntos turísticos que habilitan esta posibilidad. Tal es el ejemplo de Marta que vende artesanías en el parque semana por medio. A partir de esta experiencia comenzó a hablar español. En una ocasión, Marta (traducida por su hija) cuenta que había comprado unas artesanías talladas a un señor de otra zona de la provincia y la había vendido al doble del precio que la había comprado (entrevista conjunta, 04/11/16). A través de la artesanía Marta muestra una gran habilidad comercial y capacidad para el bilingüismo que le permiten generar nuevos recursos económicos, lo que le implica moverse fuera del ámbito doméstico. Aquí encontramos una diferencia, mientras la ONG busca incorporar a las mujeres como parte del conjunto de 
actores de la experiencia turística, son hombres jóvenes los que se interesan por esos roles y se suman como guías. Las mujeres, en cambio, se dedican muchas veces a la comercialización de artesanías, realizadas por sus familias o a través de compra y venta a otras. Es una forma de participación diferente en la experiencia turística, pero forman parte del mismo esquema.

Estas experiencias donde las mujeres narran su vida cotidiana no presentan un único modelo de transformación, pero sí permite visualizar procesos de cambio en este contexto. Tampoco significan rupturas con los modelos hegemónicos para el grupo, ya que muchas de ellas cumplen también con los roles tradicionales para las mujeres. Pero a su vez, los espacios de liderazgos implican desarrollar saberes específicos como el manejo del español, gestiones frente a actores del Estado, formación profesional fuera de la comunidad, habilidades de comercialización, etc. Las experiencias de estas mujeres amplían las posibilidades que se le presentan a las mujeres sobre "su deber ser". Ese poder no se moldea únicamente por recibir una retribución económica sino también al ser consultadas por otras personas de la comunidad, reconociendo su especificidad, su formación y avalando su toma de decisiones. En esta línea, consideramos que los cambios que conllevan estos liderazgos no son únicamente propiedad individual de las mujeres sino de las relaciones de género en que ellas están inmersas ya que la mayor parte de las veces posicionarse en esos roles (sea como cacicas, auxiliares bilingües, agentes sanitarias, entre otras) supone una elección de la comunidad y un consenso de la misma.

\section{MUJERES Y LIDERAZGOS. APUNTES DE CIERRE}

Las innovaciones de los roles de liderazgo en las poblaciones guaraníes representan una de las transformaciones más drásticas de las dinámicas cotidianas. A las tradicionales autoridades religiosas, guías espirituales de las comunidades que producen la vinculación con los dioses, que han registrado las etnografías más clásicas de la región (CÁDOGAN, 1997; MELIÁ, 1981; 1991; CLASTRES, 1993; MÉTRAUX, 1996; NIMUENDAJÚ, 1954; SCHADEN, 1998; SUSNIK, 1983) y que sostienen su desempeño asociado al conocimiento que brinda la experiencia encarnada en el tiempo, les es ajena la representación frente al Estado. Las autoridades que desempeñan esa tarea se generan ad-hoc y reponen otros requisitos, entre los que podemos destacar ser elegidos por consenso, ser bilingües, tener 
la habilidad de leer y redactar documentos y representar el bien común. Estas autoridades pueden desempeñarse por tiempos variables y surgen en la instancia en que el Estado interpela a los grupos (GOROSITO KRAMER, 2006).

En esta misma línea argumental sostenemos que los y las auxiliares bilingües, así como los y las agentes sanitarios/as, expresan ciertas formas de autoridad para las comunidades. Esto puede verse asociado a los bienes que circulan respecto de estas tareas, bienes materiales y simbólicos. Pero también a que su desempeño es elegido por el grupo y su tarea es avalada o removida por el mismo grupo con toda la conflictividad que esto pueda aparejar. Sin desconocer que son tareas laborales remuneradas, lo que implica per-se una posición de poder.

$\mathrm{Y}$, por tanto, es muy relevante considerar la apertura que ha implicado para las mujeres sumarse en estas tareas en la medida en que las posiciona de un modo muy particular en relación con los recursos económicos. Las dinámicas de formación, en todos los casos suponen una experiencia externa al grupo, en conjunto con otras personas de la comunidad, así como la ubicación permanente de contacto con médicos, docentes, etc. Esa externalidad que implica el rol supone una interculturalidad explicita que conlleva una articulación al interior muy compleja.

Por otro lado, abrimos la pregunta sobre si la presencia de mujeres en los ámbitos formativos de los niños y los cuidados de la salud implica una verdadera transformación o más bien, la ampliación de un tipo de tareas que ya desarrollaban las mujeres indígenas y que, además ahora, son exigencias del Estado a través de planes y programas específicos, entrelazando lógicas de género que ubican a la mujer como "cuidadora" de ella y su familia (MOORE, 2009).

\section{REFERENCIAS}

CÁDOGAN, León. Ayvu-Rapyta - textos míticos de los Mbya-guaraní del Guairá. 3. ed. Paraguay: Fundación León Cadogan; CEADUC; CEPAG, 1997 [1959]. 322p.

CANTORE, Alfonsina. Ellas están mucho dentro de sus casas: una aproximación a las experiencias de las mujeres mbyá guaraní al norte de Misiones. 2017. 153p. Tesis (Licenciada en Antropología) - Facultad de Filosofía y Letras, Universidad de Buenos Aires, Argentina, 2017.

CASTELNUOVO, Natalia Biraben. Mujeres guaraníes y procesos de participación política en el noroeste argentino. Buenos Aires: Antropofagia, 2015. 304p. 
CLASTRES, Hélène. La tierra sin mal: el profetismo tupí-guaraní. Buenos Aires: Ediciones del Sol, 1993.

CEBOLLA BADIE, Marilyn 'Iñengue'. Transformarse en Mujer en la sociedad Mbya-guaraní. En: CELIGUETA, Gemma; OROBITG, Gemma; PITARCH, Pedro (Coord.). Modernidad indígena, indigeneidad e innovación social desde la perspectiva del género. Barcelona: Universidad de Barcelona, 2014. p. 27-39.

ENRIZ, Noelia; GARCÍA PALACIOS, Mariana. Deviniendo kuña va'era. En: HIRSCH, Silvia (Coord.). Mujeres indígenas de la Argetina. Cuerpo, trabajo y poder. Buenos Aires: Biblos, 2008. p. 205-30.

GARCIA PALACIOS, Mariana; PADAWER, Ana; HECHT, Ana Carolina; NOVARO, Gabriela. Mujeres indígenas: trayectorias educativas de tres referentes comunitarias en Argentina. En: NOVARO, Gabriela, PADAWER, Ana; HECHT, Ana Carolina (Coord.). Educación, pueblos indígenas y migrantes. Avances desde México, Brasil, Bolivia, Argentina y España. Buenos Aires: Biblos, 2016. p. 161-19.

GÓMEZ, Mariana. Modernidad y género en mujeres indígenas tobas (qom) del Chaco centro-occidental, Argentina: algunas reflexiones. En: GREGOR-STRÖBELE, Juliana; WOLLRAD, Dörte (Coord.). Espacios de Género: Adlaf Congreso Anual 2012. Buenos Aires: Nueva Sociedad; Fundación Friedrich Ebert; Adlaf, 2013. p. 288-301.

GÓMEZ, Mariana. Guerreras y tímidas doncellas del Pilcomayo. Las mujeres tobas (qom) del oeste de Formosa. Buenos Aires: Editorial Biblios, 2016. 394p.

GOROSITO KRAMER, Ana María. Liderazgos guaraníes: breve revisión histórica y nuevas notas sobre la cuestión. Avá, Misiones, n. 9, p. 11-27, ago. 2006.

HECHT, Ana Carolina; ENRIZ, Noelia; GARCÍA PALACIOS, Mariana; ALIATA, Soledad; CANTORE, Alfonsina. Yo quiero estudiar por mi comunidad. Trayectorias educativas de maestras qom/toba y mbyá guaraní en Argentina. Cuadernos de Antropología Social, Buenos Aires, n. 47, p. 105-22, 2018.

HIRSCH, Silvia. Maternidad, trabajo y poder: cambios generacionales en las mujeres guaraníes del norte argentino. En: HIRSCH, Silvia (Coord.). Mujeres indígenas en la Argentina. Cuerpo, trabajo y poder. Buenos Aires: Biblos, 2008. p. 231-51.

LAMAS, Marta. Usos, dificultades y posibilidades de la categoría género. Papeles de Población, Toluca, México, v. 5, n. 21, p. 147-78, 1999. 
LARRICQ, Marcelo. Ipytuma, construcción de la persona entre los Mbyà-Guaraní. Posadas: Editorial Universitaria UNaM, 1993. 127p.

MELIÁ, Bartolomé. El "modo de ser guaraní" en la primera documentación Jesuitica (1594-1639). Revista de Antropologia, São Paulo, v. 24, p. 1-24, 1981.

MELIÁ, Bartolomé. El guaraní: experiencia religiosa. Asunción: CEADUC; CEPAG, 1991.

MÉTRAUX, Alfred. Etnografía del gran chaco. Asunción: El lector, 1996 [1948].

MISIONES ONLINE. Ruperta y Eva, las historias de las dos mujeres caciques, 10 fev. 2015. Disponible en: http://misionesonline.net/2015/02/10/ruperta-y-eva-las-historias-de-lasdos-mujeres-caciques-en-la-totalidad-de-las-aldeas-mbya-guarani-de-misiones/. Acceso en: 22 set. 2017.

MOHANTY, Chandra Talpade. Bajo los ojos de occidente. Academia feminista y discursos coloniales. En: CASTILLO, Hernández; NAVAZ, Suárez (Coord.). Descolonizando el feminismo. Teorías y prácticas desde los márgenes. Madrid: Ed. Cátedra, 2008 [1984]. p. 117-64.

MOORE, Henrrieta. Antropología y feminismo. 5. ed. Madrid: Ed. Cátedra, 2009 [1991]. 265p.

NIMUENDAJú, Curt. Apontamentos sobre os guarani. Revista do Museu Paulista, São Paulo, v. 8, 1954.

PISSOLATO, Elizabeth. A duração da pessoa: mobilidade, parentesco e xamanismo Mbya (guarani). São Paulo: Editora UNESP; ISA; Rio de Janeiro: NuTI, 2007. 445p.

REMORINI, Carolina. Mujeres mbya: vida cotidiana y cuidado infantil. Estudio etnográfico en comunidades mbya del Valle del Cuña Piru (Misiones). Cuadernos del Instituto Nacional de Antropología y Pensamiento Latinoamericano, Buenos Aires, v. 20, p. 301-16, 2003.

SCHADEN, Ergon. Aspectos fundamentales de la cultura guaraní. 3. ed. Asunción: Universidad Católica, 1998 [1954]. 238p.

SEGATO, Rita Laura. Género y colonialidad: en busca de claves de lectura y de un vocabulario estratégico descolonial. En: BIDASECA, Karina; VAZQUEZ LABA, Vanesa (Coord.). Feminismos y Poscolonialidad: descolonizando el feminismo desde y en América Latina. Buenos Aires: Ediciones Godot, 2010.

SCOTT, Joan. Género ¿Todavía una categoría útil para el análisis? Revista Diógenes, [s.l.], v. 57, n. 1, p 7-14, 2010. 
SUSNIK, Branislava. Los aborígenes del Paraguay. Asunción: Museo Etnográfico Andrés Barbero, 1983.

\section{Sobre las autoras:}

Alfonsina Cantore: Profesora y Licenciada de Cs. Antropológicas por la Universidad de Buenos Aires (UBA) y cursó, posteriormente, la maestría en Antropología Social. Actualmente se desempeña como becaria doctoral UBACYT en el Instituto de Ciencias Antropológicas (ICA) de la misma universidad. Participa de diversos grupos de investigación referidos a poblaciones indígenas principalmente sobre educación intercultural y salud. Sus investigaciones abordan diversas temáticas sobre mujeres indígenas en escenarios urbanos y rurales, en sus relaciones familiares y de cuidado de la salud. Adoptando, principalmente, una perspectiva etnográfica y de género.E-mail: alfonsinacantore@gmail.com

Noelia Enriz: Doctora, Licenciada y Profesora en Cs. Antropológicas por la Universidad de Buenos Aires (UBA). Actualmente, es Investigadora Adjunta de CONICET. Dirige diversos proyectos de investigación referidos a las poblaciones indígenas, la educación intercultural y la niñez. Su principales investigaciones han estado referidas al abordaje de los niños y niñas indígenas y/o étnicamente identificados en escenarios urbanos y rurales, en sus relaciones familiares, escolares y formativas en general. Etnografía con niños y niñas en escenarios comunitarios, entrevistas antropológicas. Indagaciones relativas a los saberes y conocimientos de los niños y niñas. Problemáticas de derechos, salud, educación, etc. E-mail: nenriz@yahoo.com.ar

Recibido el 2 de octubre de 2018

Aprobado para su publicación el 19 de febrero de 2019 
